\title{
Health Indicators of Native Hawaiian and Pacific Islanders in the United States
}

\author{
Karen L. Moy $\cdot$ James F. Sallis $\cdot$ Katrine J. David
}

Published online: 24 October 2009

(c) The Author(s) 2009. This article is published with open access at Springerlink.com

\begin{abstract}
This study aimed to describe health indicators and behaviors of Native Hawaiian and Pacific Islander (NHPI) adults and to compare findings to previous reports on US NHPI and the US population. A sample of $N=100$ (56 M, 44 F) NHPI adults aged 40-59 years completed an anonymous questionnaire addressing education and household income, tobacco use, physical activity, fruit and vegetable $(\mathrm{F} \& \mathrm{~V})$ consumption, cancer screening and health status. Objective measures of height and weight were taken to calculate body mass index (BMI). The study sample consisted of $49 \%$ current smokers and the majority was not meeting guidelines for physical activity $(80 \%)$ or $\mathrm{F} \& \mathrm{~V}$ consumption (99\%). Cancer screening rates ranged from 0 to $57 \%$ and were higher among females. Mean BMI was $33.9 \pm 7.5 \mathrm{~kg} / \mathrm{m}^{2}$ and $95 \%$ were overweight or obese. While $36.7 \%$ were hypertensive, only $11.1 \%$ were taking prescribed medication. Compared to both the general US population and available data for US NHPI, study participants reported higher prevalence of obesity and chronic conditions (hypertension, high cholesterol, diabetes, and angina/CHD) and lower levels of physical activity, F\&V
\end{abstract}

K. L. Moy $(\bowtie)$

Department of Family and Preventive Medicine, University of California, San Diego, 3900 Fifth Avenue, Suite 310,

San Diego, CA 92103, USA

e-mail: klmoy@ucsd.edu

J. F. Sallis

Department of Psychology, San Diego State University, 3900 Fifth Avenue, Suite 310, San Diego, CA 92103, USA

K. J. David

Rady Children's Hospital and Health Center,

3020 Children's Way, San Diego, CA 92123, USA consumption and cancer screening rates. Study findings contribute to the limited knowledge regarding health behaviors of US NHPI. Comparisons to US data increase evidence of NHPI health disparities, while comparisons to previous NHPI studies emphasize the magnitude of unhealthy lifestyle behaviors and subsequent adverse health conditions for this particular sample. Further improvements to community outreach and recruitment strategies could successfully encourage high-risk individuals to participate in health promotion and behavior intervention studies to improve NHPI health behaviors.

Keywords Native Hawaiian and Pacific Islanders . Physical activity - Tobacco - Cancer screening . Obesity

\section{Introduction}

Native Hawaiian and Pacific Islanders (NHPI) represent cultural groups having origins in any of the Pacific Islands in Polynesia, Micronesia or Melanesia [1]. Due to their relatively small numbers in the US, data for both Asian and Pacific Islander (API) populations, representing over forty diverse cultures, have historically been aggregated into one category [2-6]. As a group, API were associated with favorable health profiles $[7,8]$ and inadvertently acquired the "healthy minority" label. However, health-related studies, mostly conducted in Hawai'i and the South Pacific, highlight a multitude of health disparities for NHPI, providing evidence of a generally poor health status. Available literature reports typically low level s of physical activity [9-16], poor diets (high in fat, low in fruits and vegetables $(\mathrm{F} \& \mathrm{~V})[12,17,18]$ high tobacco use $(30.9 \%)$ [19], high rates of overweight and obesity $[12,13,15,18,20-23]$, and 
consistently high rates of chronic diseases such as cancer (breast $150 \%$, ovarian $200 \%$, cervical $500 \%$ compared to US 118, 13 and 8\%, respectively) [24], diabetes and heart disease [25, 26]. Life expectancies at birth for Hawaiian, Samoan, and Guamanian males $(71.5,71.0$ and 72.4 years, respectively) and females (77.2, 74.9 and 76.1 years, respectively) are lower than white men and women in the US [27-29]. NHPI are less likely to be aware of adverse health conditions and therefore less likely to seek medical care [26, 30]. For example, Native Hawaiians in Hawai'i display one of the worst health profiles, the highest mortality rates for most chronic diseases, and subsequently the shortest life expectancy [30].

The diversity and health disparities among NHPI in the US were acknowledged by Healthy People 2010, which established ten leading health indicators to serve as a set of measures to provide a snapshot of the nation's health [31]. Limited data indicated that, compared to the general population, NHPI typically experienced poorer health, displayed lower levels of educational attainment, and higher rates of poverty. However, for the top three leading health indicators (physical activity, overweight and obesity, and tobacco use), data for NHPI were either not collected, had not been analyzed, or did not meet the criteria for statistical reliability, data quality or confidentiality [31].

In 1997, the US Office of Management and Budget officially acknowledged the diversity of API and the importance of identifying health disparities within NHPI apart from the much larger Asian populations. Classification standards for collecting and reporting federal statistics on race and ethnicity were revised to disaggregate API into two separate groups: Asian Americans and Native Hawaiian and Pacific Islanders [32].

In the US, there was a $140 \%$ growth rate of NHPI between 1990 and 2000 [33], and by 2006, this number exceeded one million [1]. Although representing only $0.3 \%$ of the nation's population, the annual growth rate from 2005 to 2006 was $1.7 \%$ (or 17,000). The highest increase was seen in California $(3,400)$, which accounts for $>25 \%$ (260,000) of the NHPI living in the US (second only to Hawai'i) [34-36]. Compared to the general population with a median age of 36.4 years and $25 \%<18$ years, NHPI are a relatively young group (median age of 28.6 years with $30 \%$ $<18$ years) $[1,35]$.

Additional information regarding ethnic-specific health behaviors for NHPI contributes to the limited data available for this high risk group. The primary aim of this study was to describe physical activity, F\&V consumption, tobacco use and cancer screening behaviors in NHPI adults residing in San Diego County. Secondary aims were to compare findings to available data on US NHPI and the US population.

\section{Methods}

The San Diego State University Research Foundation Institutional Review Board approved this cross-sectional study. A community leader recruited individuals attending the San Diego Pacific Islander Festival and local church and community functions. Since cancer screening behaviors were variables of interest, the sample of NHPI adults was limited to 40-59 years. Participants were asked to complete an anonymous questionnaire and undergo measures of height and weight. Overall, 343 (219 M, 124 F) individuals were approached to reach the final sample of $N=100(56 \mathrm{M}, 44 \mathrm{~F})$ (response rate $=29.2 \%)$. Questions from existing surveys that had evidence of validity and reliability were compiled to create the questionnaire administered in this study [37-40]. Socioeconomic indicators were educational background and annual household income. Physical activity was measured with the New Zealand Physical Activity Questionnaire-short form [41] which was modified from the International Physical Activity Questionnaire (IPAQ-short). Questions pertaining to tobacco use, F\&V consumption, cancer screening behaviors and health status originated from the Behavioral Risk Factor Surveillance Surveys (BRFSS) [42, 43]. Aside from physical activity questions, the questionnaire was self-administered and the above variables consisted of 3036 questions, depending on participant age and gender. A stadiometer (Ohaus ES 200L) was used to measure height to the nearest $0.1 \mathrm{~cm}$ and a digital scale (Conair WW33) measured weight to the nearest $0.1 \mathrm{~kg}$. Body mass index (BMI) was calculated as weight $(\mathrm{kg})$ divided by height $\left(\mathrm{m}^{2}\right)$.

Data coding, scoring and categorizing followed established protocols from the respective questionnaires. Education levels were categorized as 'less than high school education' ( $<7$ th grade, junior high/middle school, some high school), 'at least high school education' (completed high school, some college or vocational training) and 'have bachelor's degree (completed college or university, completed graduate degree). Participants who were current smokers were categorized by frequency ('everyday' and 'some days'). Total duration (min/week) of walking, moderate- and vigorous-intensity physical activity was computed by multiplying the frequency (days/week) and average daily duration (min/day). MET values for walking (3.3 METs), moderate- (4.0 METs) and vigorous-intensity (8.0 METs) activity were multiplied by total duration to calculate total MET-min/week. Participants were classified into 'low', 'moderate' or 'high' activity categories according to the following standard scoring criteria, and those in 'moderate' and 'high' activity categories were further classified as 'meeting' current physical activity guidelines [44]: 
- Low: individuals who do not meet criteria for 'moderate' or 'high'

- Moderate: individuals who reported either of the following criteria:

- Vigorous-intensity activity on $\geq 3$ days/week for $\geq 20 \mathrm{~min} /$ day

- Moderate-intensity activity on $\geq 5$ days/week for $\geq 30 \mathrm{~min} /$ day

- Walking, moderate- or vigorous-intensity activity on $\geq 5$ days/week achieving $\geq 600$ MET-min per week

- High: individuals who reported either of the following criteria:

- Vigorous-intensity activity on $\geq 3$ days/week achieving $\geq 1500 \mathrm{MET}-\mathrm{min} /$ week

- Walking, moderate- or vigorous-intensity activity on $>7$ days/week achieving $\geq 3000$ MET-min/ week

Responses to dietary questions were converted to average daily servings and total daily $\mathrm{F} \& \mathrm{~V}$ consumption included fruit juice, fruit, green salad, potatoes, carrots and vegetables (as reported in BRFSS). Cancer screening questions asked women if they ever had a mammogram, clinical breast exam, or Pap test, asked men if they ever had a prostate-specific antigen (PSA) test or a digital rectal exam, and asked respondents $\geq 50$ years if they ever had a blood stool test, sigmoidoscopy or colonoscopy. Standard BMI categories were used to classify participants as normal weight $\left(<25.0 \mathrm{~kg} / \mathrm{m}^{2}\right)$, overweight $\left(25.0-29.9 \mathrm{~kg} / \mathrm{m}^{2}\right)$ or obese $\left(\geq 30.0 \mathrm{~kg} / \mathrm{m}^{2}\right)$. Health status was assessed by asking if the respondent had ever been told by a doctor, nurse, or other health professional that they had high blood pressure, high blood cholesterol, diabetes or cardiovascular disease (in the form of a heart attack, angina or coronary heart disease, or stroke).

\section{Statistical Analyses}

A target sample size of $N=100$ was set to detect small effect sizes (Cohen's $d=0.20$ ) at an alpha of 0.05 and power of 0.80 . Statistical analyses were conducted using SPSS 15.0, and 'Don't know/Not sure' and 'Refused' responses were set to 'Missing'. One outlier was identified for self-reported total physical activity (750 min/ week). Preliminary analysis of physical activity data conducted with and without one outlier's data showed no differences, so this participant's data remained in the analyses. Independent $t$-tests were conducted to examine differences in health behaviors between NHPI men and women.
Comparison Samples

Present study data are presented in comparison to available data for US NHPI and the general US population, and came from multiple resources. The National Health and Nutrition Examination Survey (NHANES) collects data through interviews and physical examinations to assess the prevalence of chronic conditions in the population. Height, weight and body mass index (BMI) calculations were compared to objective measures from NHANES (19992002) on Non-Hispanic White adults aged 40-59 years [45]. The BRFSS is a telephone-administered health survey designed to track health information related to leading causes of death in the US BRFSS data specific to level of education, household income, tobacco use, F\&V consumption, cancer screening and the majority of health status variables (high cholesterol, heart attack, angina or coronary heart disease, and stroke) were reported for 45- to 54-year-olds from all 50 states and the District of Columbia for 2006 and 2007 [43, 46]. Comparative data on the prevalence of hypertension and medication were obtained for 2007 from the Centers for Disease Control and Prevention [47]. National physical activity data was obtained from an international study that surveyed $N=4,671$ US adults with a similar instrument and scoring protocol (response rate $30.9 \%$ ) [48].

Data pertaining to US NHPI were retrieved from several national resources, including the Asian Pacific Islander American Health Forum (APIAHF) [3, 34], the US Census [1, 49], the California Health Interview Survey (CHIS) [50], and a National Institutes of Health (NIH) report [51]. Ethnic-specific data for NHPI subgroups came from the US Census, APIAHF [25, 28], CHIS, BRFSS Hawai'i [52], the Hawai'i State Department of Health [11, 53], and three smaller research studies [30, 54, 55]. The smaller research studies used a variety of recruitment approaches, mainly conducted by community members that were somewhat similar to recruitment methods from the present study. Aluli [54] conducted clinical examinations on $N=257$ Native Hawaiians, aged 20-59 years, living in rural areas of Molokai. Participants were recruited through mail solicitations, newspaper advertisements and house-to-house canvassing of the community by Native Hawaiian physicians and outreach workers. Mishra et al. [55-57] examined health behaviors, knowledge and attitudes in Samoan adults residing in American Samoa, Hawai'i and Los Angeles. A sample of $N=1834$ Samoans aged $\geq 18$ years were randomly sampled for a cross-sectional study that involved an interviewer-administered questionnaire in either English or Samoan language. Participation was encouraged through churches, community organizations and government officials, and results 
specific to smoking and cancer screening behaviors were used for comparisons. Chiem et al. [30] assessed cardiovascular risk factors in $N=228$ Chamorro men and women, aged 19-87 years, residing in San Diego, California. Study participants were randomly sampled from the Chamorro Directory International, a telephone directory of self-identified Chamorros. Word of mouth and community newspaper advertisements encouraged participation. Research staff members were bilingual community members and the overall response rate was $62.8 \%$.

\section{Results}

A total of $100 \quad(56 \mathrm{M}, 44 \mathrm{~F})$ NHPI adults (mean age $=46.9 \pm 5.4$ years) completed the anonymous questionnaire. The ethnic composition of this sample included Samoans (57\%), Tongans (6\%), Guamanian/Chamorros (11\%), Marshallese (3\%) and NHPI reporting 'more than one race' (24\%). Participant characteristics, health behaviors, and comparable data for US NHPI and the general US population are reported in Table 1.

\section{Education and Household Income}

The proportion of the US population aged 45-54 years with less than a high school education was $6 \%$, with $92 \%$ having at least a high school education [46]. Values for NHPI in the US were 21.0 and $55-84 \%$, respectively [34, 49]. The present study's sample consisted of $15 \%$ with less than a high school education, $85 \%$ with at least a high school education and $11 \%$ with a bachelor's degree. Compared to the US, NHPI from the present sample and other studies reported more individuals with less than a high school education.

In 2000, median household income in the US was $\$ 50,046$ [49]. For NHPI, median incomes ranging from $\$ 42,062$ to $\$ 50,922$ have been reported [1, 25, 28, 34, 49] with ethnic specific data for Native Hawaiians $(\$ 44,862)$ [25] and Samoans $(\$ 40,058)$ [28]. Median household income for this sample was $\$ 50,000-\$ 59,000$, slightly higher than comparison samples.

\section{Tobacco Use}

In 2007, $22 \%$ of US adults aged 45-54 years were current smokers [46]. Available data report $17 \%$ of US NHPI as current smokers, with ethnic-specific data for Chamorros (15\%) and Hawaiians (20-27\%) [25, 30, 50, 58]. The proportion of current smokers in the present study was at least 2-3 times greater than comparison samples.
Frequency of Tobacco Use

In the US a higher proportion of adults aged 45-54 years reported smoking 'every day' $(18 \%)$ compared to 'some days' (5\%) [46]. No comparable data was available for US NHPI. About $5 \%$ of the sample from this study reported 'every day' smoking while $44 \%$ smoked 'some days'.

In the US, more males (21\%) than females (18\%) reported being current smokers. The prevalence of males and females smoking 'every day' and 'some days' was 16 vs. 13 and 6 vs. 5\%, respectively [46]. No comparable data was available for US NHPI. In the present study, more males $(52 \%)$ than females $(46 \%)$ were current smokers, although more females reported 'every day' smoking (5 vs. $11 \%$ ) while more males reported 'some day' smoking (46 vs. $41 \%)$.

\section{Physical Activity}

The proportion of US adults classified into low, moderate and high physical activity categories was 16,22 , and $62 \%$, respectively [48]. No comparable reports using the same measure of physical activity were found for US NHPI. The majority of the present study's sample was classified as low active (80\%), with 18 and $2 \%$ in the moderate and high active categories, respectively. Female study participants were significantly more active than males for walking, moderate- and vigorous-intensity activity $(P<0.05)$.

\section{Fruit and Vegetable Consumption}

For US adults aged 45-54 years, the median percentage of individuals consuming $\geq 5$ daily $\mathrm{F} \& \mathrm{~V}$ servings was $23 \%$. Overall, more females (29\%) met $\mathrm{F} \& \mathrm{~V}$ recommendations compared to males (19\%) [46]. Ethnic specific NHPI studies reported $17 \%$ of Native Hawaiians [53] and 42 and $40 \%$ of Chamorro males and females consumed $\geq 5$ daily F\&V servings [30]. Mean daily F\&V intake for this study's sample was $0.8 \pm 1.3$ servings. Females consumed more $\mathrm{F} \& \mathrm{~V}$ servings than males $(1.1 \pm 1.7$ vs. $0.6 \pm 0.9$, respectively; $P=0.06$ ), although only one female participant reported meeting current $\mathrm{F} \& \mathrm{~V}$ recommendations.

\section{Cancer Screening}

Across all cancer screening tests, US rates of 'ever' screened ranged from $24 \%$ (home blood stool test) to $90 \%$ (clinical breast exam) [43, 46]. For US NHPI, cancer screening rates ranged from $23 \%$ (home blood stool test) to $92 \%$ (clinical breast exams and mammograms for Native Hawaiians) [43, 50, 52, 53, 55, 56]. By contrast, NHPI cancer screening rates from the present study were dramatically lower, ranging from $0 \%$ (home blood stool test) 


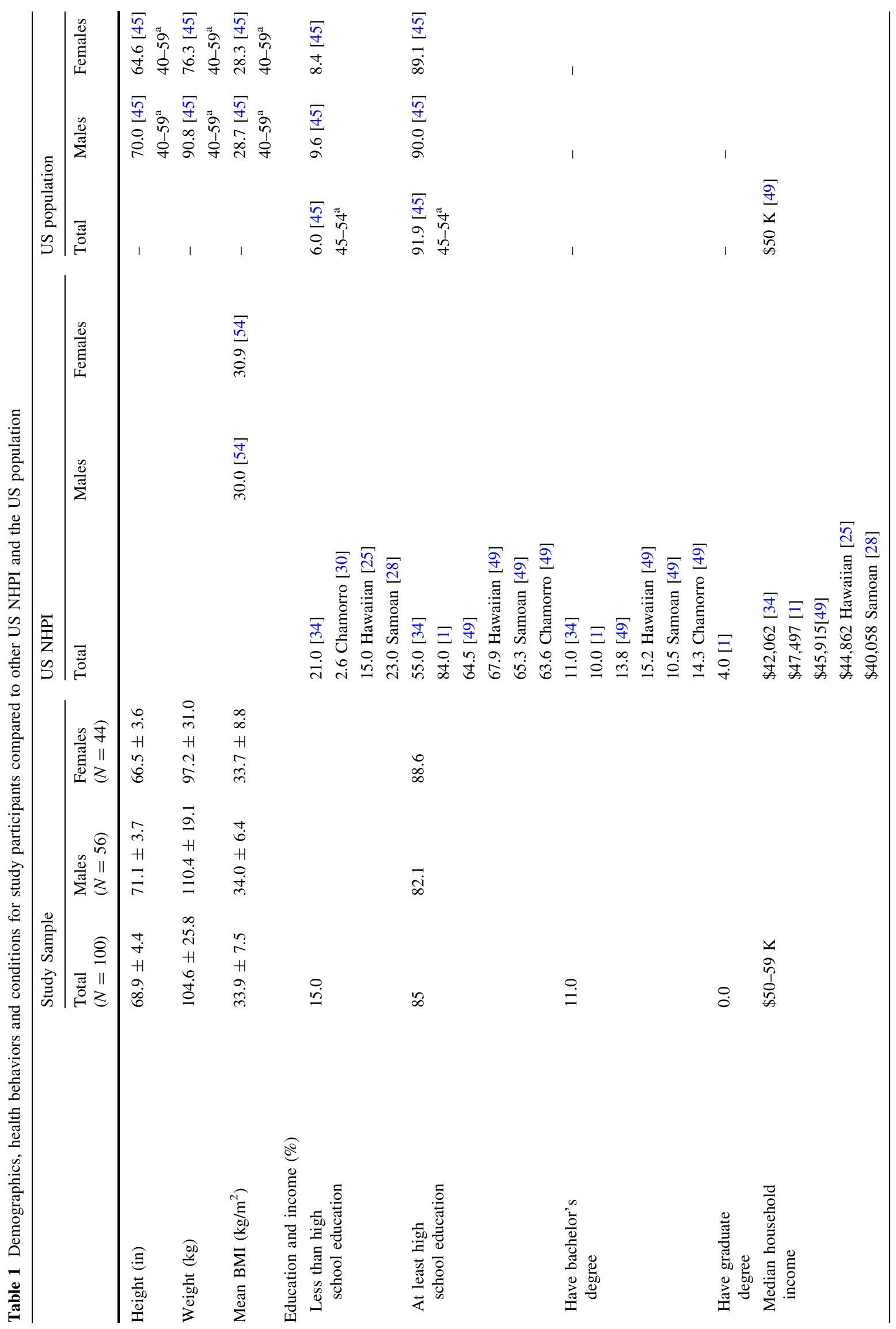




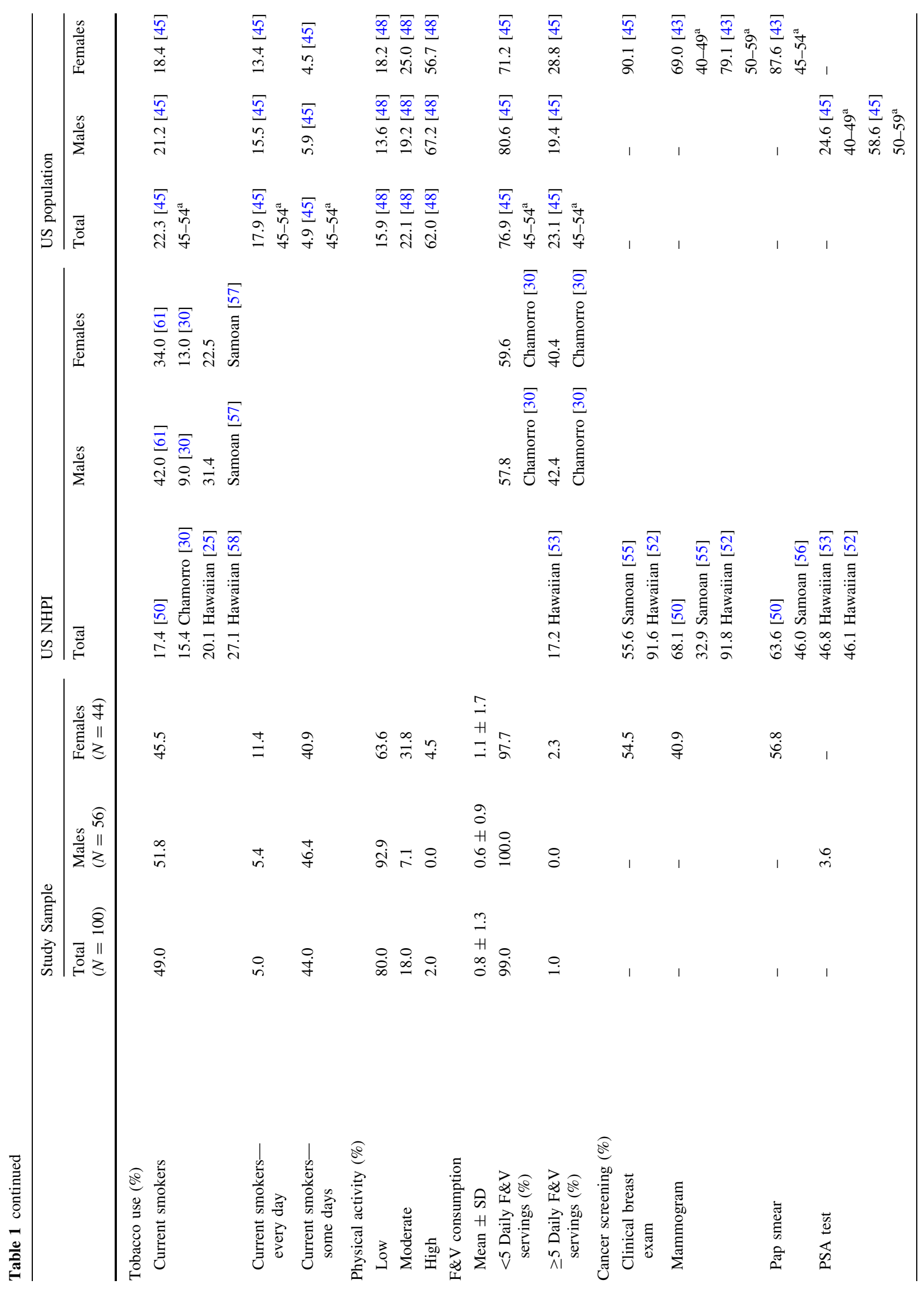




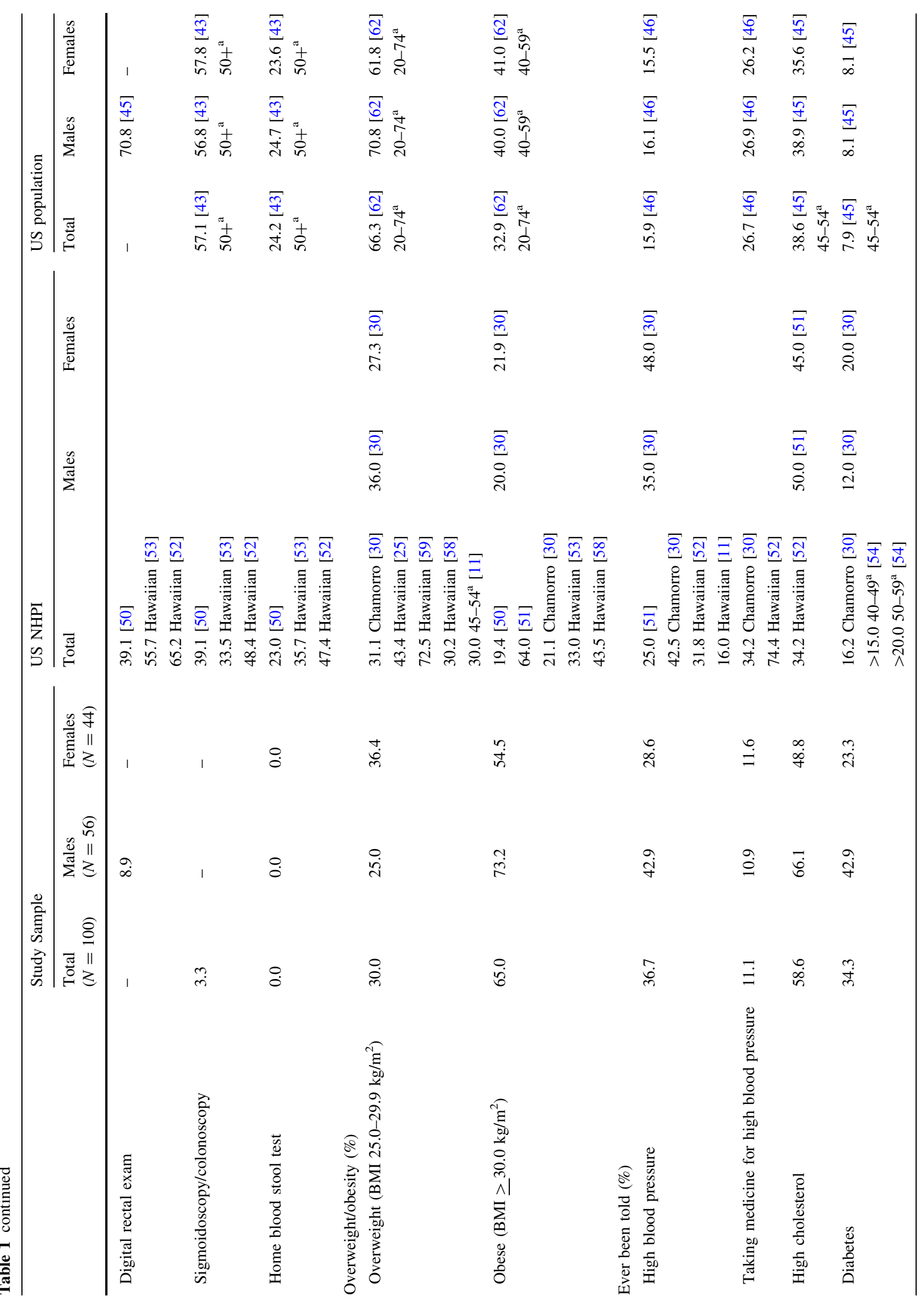




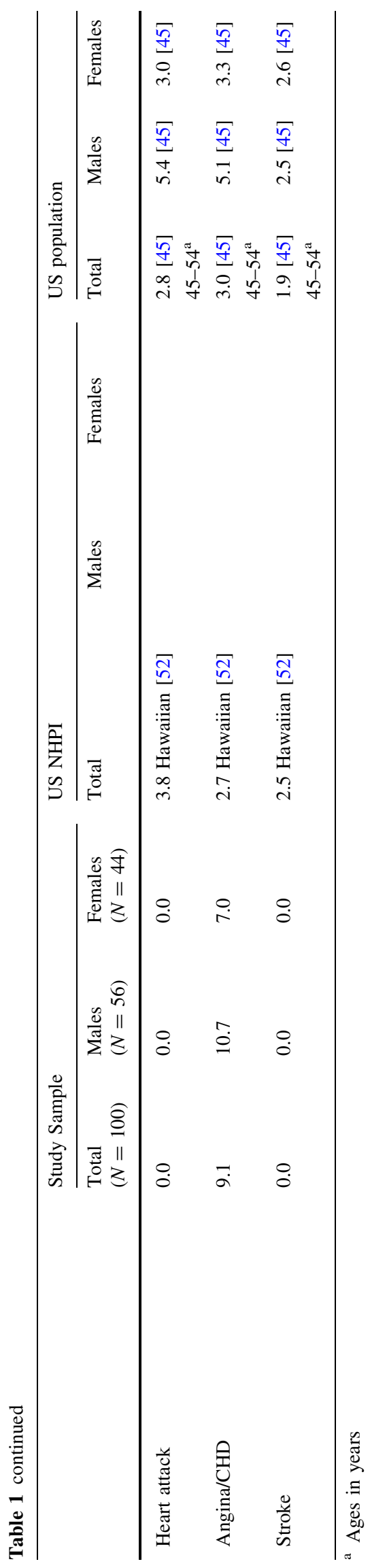

to $57 \%$ (Pap smear). Females demonstrated higher cancer screenings rates $(41-57 \%)$ than males (4-9\%).

Body Mass Index Categories

Rates of US overweight and obesity are $\sim 66$ and 33\%, respectively. The prevalence of overweight males (71\%) was higher than females $(62 \%)$ and obesity rates among 40- to 59-year-olds were 40 and $41 \%$, respectively) [45]. Available literature on NHPI subgroups have reported $31 \%$ of Chamorros ( $M=36 \%, F=27 \%$ ) [30] and 30 to $73 \%$ of Hawaiians to be overweight $[25,58,59]$. In $1993,30 \%$ of Native Hawaiians aged 45-54 years were overweight [11]. The prevalence of obesity in US NHPI varies from $19 \%$ (in California) to $64 \%$, based on multiple studies [30, 50, 51, $53,58]$. In the present study, only $5 \%$ of NHPI were classified as normal weight, while $30 \%(M=25 \%$, $F=36 \%)$ were overweight and $65 \% \quad(M=73 \%$, $F=55 \%)$ were obese. The total sample was classified as obese with a mean BMI of $33.9 \pm 7.5 \mathrm{~kg} / \mathrm{m}^{2}$.

\section{Health Status}

About $16 \%$ of the US population had been told they had hypertension and $27 \%$ of those individuals were currently taking hypertensive medications [47]. Comparable data among US NHPI report a $25 \%$ prevalence of hypertension [51]. Prevalence of hypertension was higher in Native Hawaiians (16-32\%) [11, 52] and Chamorros (43\%) [30], which also reported a higher proportion of hypertensive Hawaiians and Chamorros taking medication (74 and 34\%, respectively), compared to the US population. In the present study, $37 \%(M=43 \%, F=29 \%)$ were hypertensive, although only $11 \%(M=11 \%, F=12 \%)$ reported taking medication.

In $2007,39 \%$ of US adults aged $45-54$ years had been told by a health professional they had high cholesterol [46] compared to $34 \%$ of Native Hawaiians [52]. Another study reported $50 \%$ of NHPI males $45 \%$ of females had high cholesterol [51]. In this study's sample, high cholesterol was reported by $59 \%$ of participants, with a higher prevalence among males (66\%) compared to females (49\%).

Approximately $8 \%$ of the US population between 45 and 54 years of age reported being diagnosed with diabetes [46]. Previous studies reported diabetes in 15 and $20 \%$ of US NHPI aged 40-49 and 50-59 years, respectively [54] and $16 \%(M=12 \%, F=20 \%)$ of Chamorros [30]. Onethird (34\%) of the present study's sample were diabetic, with a higher prevalence observed in males $(43 \%)$ compared to females $(23 \%)$. These findings indicate that diabetes is 2-4 times more prevalent in NHPI compared to the general US population. 
A small proportion of the US population between 45 and 54 years reported having a heart attack (3\%), angina or coronary heart disease $(3 \%)$, or a stroke (2\%) [41], and similar data were reported for Native Hawaiians (4, 3, and $3 \%$, respectively) [52]. Although none of the present study's participants reported a previous heart attack or stroke, $9 \%(M=11 \%, F=7 \%)$ had been told they had angina or coronary heart disease.

\section{Discussion}

\section{Study Participants vs. US and NHPI Comparison} Samples

Compared to the US population, health profiles of NHPI from the present study indicated poor lifestyle behaviors and high prevalence of chronic conditions. Study participants reported dramatically lower levels of physical activity, F\&V consumption and cancer screening rates. About two-thirds of study participants were obese and prevalence of smoking and chronic diseases and conditions (with the exception of heart attack and stroke) were consistently higher than the general US population in the same age groups.

Compared to available literature on US NHPI, study participants reported similar education levels and a higher household income. Although comparable physical activity data were not found, study participants reported higher rates of smoking and lower levels of F\&V consumption. Cancer screening rates were relatively similar for NHPI females, falling within the range of previously reported studies. However, cancer screening behaviors among NHPI males and individuals aged $\geq 50$ years from the present study were extremely low. The proportion of overweight study participants was similar to previous NHPI reports, although obesity was much higher in this sample. Similar adverse health profiles were observed between study participants and US NHPI reports. However, this sample had a greater prevalence of high cholesterol, diabetes, angina or CHD, and was less likely to take hypertensive medication.

\section{Participant Outreach and Recruitment in NHPI Populations}

There is a possibility the extreme prevalence rates in this sample were related to recruitment methods. Since healthier individuals are more likely to participate in health-related research [60], further examination into participant outreach and recruitment strategies was carried out. A community representative from a local organization who was a well-known, long-time advocate for NHPI health was responsible for participant recruitment. The recruitment challenge was acknowledged since NHPI are a relatively young population. Initial recruitment efforts took place at a health booth during a NHPI festival, which yielded only 22 completed surveys (response rate $18.3 \%$ ). The entire recruitment effort lasted 8 months to achieve the target sample size of $N=100$ NHPI aged 40-59 years. Feedback from the community leader indicated the low response rate was due to survey length, which had an approximate completion time of $35 \mathrm{~min}$ (the entire survey included additional variables outside the scope of this report). Additionally, timing plays an important factor in access to the community. Group occasions such as funerals and weddings typically involve the entire community and take precedence over individual commitments. The remaining study sample was recruited through repetitive, face-to-face approaches from the community leader at local churches, meetings, and social functions. The community leader had ongoing dialogue with potential study participants on several occasions, and ultimately participation was secured after the study received 'blessings' from key community leaders (i.e., elders, ministers) who encouraged participation by underscoring the benefits associated with additional research data for the NHPI community.

This approach demonstrates an intrinsic NHPI cultural attitude which places greater emphasis on the well-being of the collective unit (i.e., community, family) rather than the individual [26]. Insight from the community leader suggests that the low levels of compliance to hypertension medication is an example of NHPI sacrificing at the individual level to benefit the family (i.e. contributing finances collectively towards household expenses and financially assisting relatives). Additionally, doctors' verbal instructions on how and when to take medications are confusing or forgotten after a couple of days and there is a tendency to take home remedies (i.e. a mixture of Aloe and water) or over the counter medications (i.e. aspirin) that may have no effect on hypertension. Core cultural values among NHPI include family, community, spirituality, and a holistic view of life and health, and strongly influence health behaviors. The holistic worldview of NHPI emphasizes the interconnectedness of all things, including the belief that spiritual health contributes to physical health, that health outcomes are dictated by God's will and individual attempts to treat or control adverse health conditions are futile.

\section{Study Limitations}

This was a convenience sample obtained by intensive community outreach and recruitment strategies. While the sample may not accurately reflect the overall NHPI population, the findings emphasize NHPI health disparities in the US. During selection of comparison studies for the US population, attempts were made to find the most recent, comparable data. For example, NHANES data were used to 
report US overweight and obesity rates because these data came from objective measures of height and weight. While several variables were measured in this study by BRFSS questions, not all BRFSS data are available for each year. The proportion of US adults meeting physical activity guidelines came from a study which used a similar questionnaire that measures duration and frequency of walking, moderate- and vigorous-intensity physical activity, although the methods of administration differed from this study (telephone- vs. interviewer-administered).

\section{Study Implications}

Findings from this study contribute to the limited knowledge regarding health behaviors of NHPI in the US comparisons to US data increase evidence of NHPI health disparities, while comparisons to other NHPI studies emphasize the magnitude of unhealthy lifestyle behaviors and subsequent adverse health conditions for this particular sample. Differences in prevalence rates across NHPI samples raise questions about the most appropriate recruitment strategies for these groups. It is unclear whether higher risk prevalence rates from the current study or lower rates from other NHPI samples are more representative. One difference was use of an anonymous survey in the present study. Evaluation of participant recruitment strategies and interpretation of results underscores the importance of how cultural beliefs may affect lifestyle behaviors and decisions. Further improvements to community outreach and recruitment strategies could provide a successful approach for including high-risk individuals in health promotion and behavior intervention studies to educate and improve NHPI health behaviors. Priorities for future research include NHPI population prevalence studies which utilize culturally appropriate recruitment and measurement methods, as well as an urgent need for behavioral interventions to reduce risk in these communities.

\begin{abstract}
Acknowledgments This study was funded in part by the National Cancer Institute Minority Institution/Cancer Center Partnership Program (grants \#U56 CA92079 and \#U56 CA92081). The authors would like to extend special thanks to Mr. Tana Lepule from the Union of Pan Asian Communities and the First Samoan Congregational Church of National City. Project partners were supported in part by WINCART: Weaving an Islander Network for Cancer Awareness, Research and Training through funds from the National Cancer Institute's Center to Reduce Cancer Health Disparities (grant \#U01CA114591). The contents of this paper are solely the responsibility of the authors and do not necessarily represent the official views of the funders.
\end{abstract}

Open Access This article is distributed under the terms of the Creative Commons Attribution Noncommercial License which permits any noncommercial use, distribution, and reproduction in any medium, provided the original author(s) and source are credited.

\section{References}

1. The American Community—Pacific Islanders: 2004. (2007). Available from: Retrieved September 17, 2008, from U.S. Census Bureau: Web site: http://www.census.gov/prod/2007pubs/acs-06. pdf.

2. Braun, K. L., Yang, H., Onaka, A. T., \& Horiuchi, B. Y. (1997). Asian and Pacific Islander mortality differences in Hawaii. Social Biology, 44, 213-226.

3. Hong, B., \& Bayat, N. (1999). National Asian American \& Pacific Islander cardiovascular health action plan: Eliminating racial and ethnic disparities in cardiovascular health: Improving the cardiovascular health of Asian American and Pacific Islander populations in the United States. San Francisco, CA: Asian Pacific Islander American Health Forum.

4. Srinivasan, S., \& Guillermo, T. (2000). Toward improved health: Disaggregating Asian American and Native Hawaiian Pacific Islander data. American Journal of Public Health, 90, 17311734.

5. Yoon, E., \& Chien, F. (1996). Asian American \& Pacific Islander health: A paradigm for minority health. JAMA, 275, 736-738.

6. Yu, E. S., \& Liu, W. (1992). US national health data on Asian Americans and Pacific Islanders: A research agenda for the 1990s. American Journal of Public Health, 82, 1645-1652.

7. James, C., Thomas, M., \& Lillie-Blanton, M. (2007). Key facts. Race, ethnicity \& medical care. Retrieved September 17, 2008, from Kaiser Family Foundation Web site http://www.kff.org/ minorityhealth/upload/6069-02.pdf.

8. Ries, L. A. G., Melbert, D., Krapcho, M., Stinchcomb, D. G., Howlader, N., \& Horner, M. J., et al. (2008). SEER Cancer Statistics Review, 1975-2005. Retrieved September 17, 2008, from National Cancer Institute, Surveillance, Epidemiology and End Results Web site http://seer.cancer.gov/csr/1975_2005/.

9. Abbott, W., Scragg, R., \& Marbrook, J. (2001). Differences in disease frequency between Europeans and Polynesians: Directions for future research into genetic risk factors. Pacific Health Dialog, 8, 129-156.

10. Bell, E. A., \& Rolls, B. J. (2001). Energy density of foods affects energy intake across multiple levels of fat content in lean and obese women. American Journal of Clinical Nutrition, 73, 10101018.

11. Hawai'i State Department of Health. (1993). Hawai'i's health risk behaviors, 1993. Honolulu, HI: Hawai'i Department of Health.

12. Lako, J. V., \& Nguyen, V. C. (1991). Dietary patterns and risk factors of diabetes mellitus among urban indigenous women in Fiji. Asia Pacific Journal of Clinical Nutrition, 10, 188-193.

13. Mavoa, H. M., \& McCabe, M. (2008). Sociocultural factors relating to Tongans' and Indigenous Fijians' patterns of eating, physical activity and body size. Asia Pacific Journal of Clinical Nutrition, 17, 375-384.

14. McAnulty, J., \& Scragg, R. (1996). Body mass index and cardiovascular risk factors in Pacific Island Polynesians and Europeans in New Zealand. Ethnicity and Health, 1, 187-195.

15. Moy, K. L. (2005). Physical activity and fitness measures in New Zealand: A study of validation and correlation with cardiovascular risk factors. Doctoral dissertation, University of Auckland, New Zealand. Retrieved September 7, 2008, from The University of Auckland Library Web site http://hdl.handle.net/2292/305.

16. Simmons, D., Thompson, C. F., \& Volklander, D. (2001). Polynesians: Prone to obesity and type 2 diabetes mellitus but not hyperinsulinaemia. Diabetic Medicine, 18, 193-198.

17. Jackson, R. (1997). Dietary genocide: Eating to an early death in Micronesia. Pacific Health Dialog, 4, 88-89. 
18. Gill, T., Hughes, R., Tunidau-Schultz, J., Nishida, C., Galea, G., \& Cavalli-Sforza, T. (2002). Obesity in the Pacific: Too big to ignore. Retrieved September 17, 2008, from World Health Organization Web site http://www.wpro.who.int/publications/ pub_9822039255.htm.

19. Centers for Disease Control and Prevention. (2000). Health disparities affecting minorities: Native Hawaiians and other Pacific Islanders. Retrieved September 23, 2008, from Centers for Disease Control and Prevention, Office of Minority Health and Health Disparities Web site http://www.cdc.gov/omhd/brochures/ pdfs/NHOPI.pdf.

20. Klatsky, A. L., \& Armstrong, M. A. (1991). Cardiovascular risk factors among Asian Americans living in northern California. American Journal of Public Health, 81, 1432-1438.

21. McGarvey, S. T. (1991). Obesity in Samoans and a perspective on its etiology in Polynesians. American Journal of Clinical Nutrition, 53, 1586S-1594S.

22. Pawson, I. G. (1986). The morphological characteristics of adults. In P. T. Baker, J. M. Hanna, \& T. S. Baker (Eds.), The changing samoans: Behavior and health in transition. New York: Oxford University Press.

23. Pinhey, T. K., Heathcote, G. M., \& Rarick, J. (1994). The influence of obesity on the self-reported health status of Chamorros and other residents of Guam. Asian American and Pacific Islander Journal of Health, 2, 195-211.

24. Centers for Disease Control and Prevention. (2004). United States cancer statistics. Retrieved September 17, 2008, from Centers for Disease Control and Prevention National Program of Cancer Registries Web site http://apps.nccd.cdc.gov/uscs/Table. aspx?Group=TableAll\&Year=2004\&Display $=$. .

25. Gem, P., Daus, M. A., Bormet, M., Trieu, S. L. (2006). Health brief: Native Hawaiians in the United States. Retrieved September 17, 2008, from Asian Pacific Islander American Health Forum Web site http://www.apiahf.org/resources/pdf/Native_ Hawaiians_in_the_United_States.pdf.

26. Wergowske, G., \& Blanchette, P. L. (2001). Health and health care of elders from Native Hawaiian and other Pacific Islander backgrounds. Retrieved September 23, 2008, from Stanford University Web site http://www.stanford.edu/group/ethnoger/ nativehawaiian.html.

27. Palafox, N. A., \& KáanóI, M. (2000). Health disparities among Pacific Islanders. Closing the gap: A newsletter of the office of minority health. Retrieved September 21, 2008, from United States Department of Health \& Human Services, Office of Minority Health Web site http://www.omhrc.gov/assets/pdf/checked/ Health\%20Disparities\%20Among\%20Pacific\%20Islanders.pdf.

28. Gem, P., Daus, M. A., Bormet, M., \& Trieu, S. L. (2006). Health brief: Samoans in the United States. Retrieved September 17, 2008, from Asian Pacific Islander American Health Forum Web site http://www.apiahf.org/resources/pdf/Samoans_in_the_United_ States.pdf.

29. Jackson, Y. (2006). Encyclopedia of multicultural psychology. University of Kansas: Sage.

30. Chiem, B., Nguyen, V., Wu, P. L., Ko, C. M., Cruz, L., \& Sadler, G. B. (2006). Cardiovascular risk factors among Chamorros. BMC Public Health, 6, 298.

31. Unite States Department of Health and Human Services. (2000). Healthy People 2010. A systematic approach to health improvement. Retrieved September 23, 2008, from Healthy People 2010 Web site http://www.healthypeople.gov/document/ html/uih/uih_2.htm.

32. Office of Management, Budget. (1997). Revisions to the standards for the classification of federal data on race and ethnicity. Federal Register, 62, 58781-58790.

33. Grieco, E. M. (2001). The Native Hawaiian and other Pacific Islander population: Census 2000 brief. 2001. Retrieved
September 17, 2008, from United States Census Bureau Web site http://www.census.gov/prod/2001pubs/c2kbr01-14.pdf.

34. Samad, B., Liu, J. T., Torres, A., \& Cavosora, R. J. P. (2004). Diverse communities, diverse experiences: The status of Asian Americans \& Pacific Islanders in the US: A review of six socioeconomic indicators and their impact on health. Retrieved September 17, 2008, from Asian Pacific Islander American Health Forum Web site http://www.apiahf.org/resources/index. htm.

35. IMDiversity. (2007). Minority population tops 100 millionRelease by the US Census Bureau. 2007. Retrieved September 23, 2008, from IMDiversity Web site http://www.imdiversity.com/ villages/careers/news/census_minority_population_2007.asp.

36. Asian American Studies Center. (2008). Statistical portrait of Asian Americans, Native Hawaiians, and Other Pacific Islanders. Retrieved September 23, 2008, from University of California, Los Angeles, Asian American Studies Center Web site http://www.aasc.ucla.edu/archives/census2008portal.htm.

37. Alexander, A., Bergman, P., Hagstromer, M., \& Sjostron, M. (2006). IPAQ environmental module: Reliability testing. Journal of Public Health, 14, 76-80.

38. Bergmann, M. M., Byers, T., Freedman, D. S., \& Mokdad, A. (1998). Validity of self-reported diagnoses leading to hospitalization: A comparison of self-reports with hospital records in a prospective study of American adults. American Journal of Epidemiology, 147, 969-977.

39. Nelson, D. E., Holtzman, D., Bolen, J., Stanwyck, C. A., \& Mack, K. A. (2001). Reliability and validity of measures from the Behavioral Risk Factor Surveillance System. Social and Preventive Medicine, 46(Suppl 1), S3-S42.

40. Nelson, D. E., Powell-Griner, E., Town, M., \& Kovar, M. G. (1993). A comparison of national estimates from the National Health Interview Survey and the Behavioral Risk Factor Surveillance System. American Journal of Public Health, 93, 1335-1341.

41. Moy, K. L., Scragg, R. K., McLean, G., \& Carr, H. (2005). The New Zealand physical activity questionnaires: Validation by heart-rate monitoring in a multiethnic population. Journal of Physical Activity and Health, 5(Suppl 1), 45-61.

42. Centers for Disease Control and Prevention. (2005). Behavioral Risk Factor Surveillance System Survey Questionnaire. Retrieved September 17, 2008, from United States Department of Health and Human Services, Centers for Disease Control and Prevention Web site http://www.cdc.gov/brfss/questionnaires/pdf-ques/2005 brfss.pdf.

43. Centers for Disease Control and Prevention. (2006). Behavioral Risk Factor Surveillance System survey data. Retrieved September 17, 2008, from United States Department of Health and Human Services, Centers for Disease Control and Prevention Web site http://www.cdc.gov/brfss.

44. IPAQ Research Committee. (2005). Guidelines for data processing and analysis of the international physical activity questionnaire (IPAQ)-Short and long forms. Retrieved September 17, 2008, from international physical activity questionnaire Web site http://www.ipaq.ki.se/scoring.htm.

45. McDowell, M. A., Fryar, C. D., Hirsch, R. \& Ogden, C. L. (2005). Anthropometric reference data for children and adults: US population, 1999-2002. Retrieved September 17, 2008, from Advance Data from Vital and Health Statistics Web site http://www.cdc.gov/nchs/data/ad/ad361.pdf.

46. Centers for Disease Control and Prevention. (2007). Behavioral Risk Factor Surveillance System survey data. Retrieved September 17, 2008, from United States Department of Health and Human Services, Centers for Disease Control and Prevention Web site http://www.cdc.gov/brfss.

47. National Center for Health Statistics. (2007). Health, United States, 2007 with chartbook on trends in the health of Americans. 
Retrieved September 23, 2008, from Centers for Disease Control and Prevention Web site http://www.cdc.gov/nchs/data/hus/ hus07.pdf.

48. Bauman, A. E., Bull, F. C., Chey, T., Craig, C. L., Ainsworth, B. E., Sallis, J. F., et al. (2009). The International prevalence study on physical activity: Results from 20 countries. International Journal of Behavioral Nutrition and Physical Activity, 6, 21-31.

49. United States Census Bureau. (2000). United States Census 2000: Questions. 2000. Retrieved September 17, 2008, from United States Census Bureau Web site http://www.census.gov/dmd/ www/2000quest.html.

50. California Health Interview Survey. (2001). Retrieved September 17, 2008, from University of California, Los Angeles, California Health Interview Survey Web site http://www.chis.ucla.edu.

51. National Institutes of Health, National Heart, Lung, and Blood Institute. (2000). Addressing cardiovascular health in Asian Americans and Pacific Islanders: A background report. Retrieved September 23, 2008, from the National Institutes of Health, National Heart, Lung, and Blood Institute Web site http://www. nhlbi.nih.gov/health/prof/heart/other/aapibkgd/aapibkgd.pdf.

52. Hawai'i State Department of Health. (2007). State of Hawai' $i$ : Behavioral Risk Factor Surveillance System. Retrieved September 23, 2008, from Hawai'i Department of Health Web site http://www.Hawaii.gov/health/statistics/brfss/brfss2007/ demo07.html.

53. Hawai'i State Department of Health. (2004). Hawai'i cancer facts \& Figs 2003-2004. Retrieved September 23, 2008, from Hawai'i Department of Health Web site http://www.Hawaii.gov/ health/statistics/other-reports/cancer2003-04.pdf.

54. Aluli, N. E. (1991). Prevalence of obesity in a Native Hawaiian population. American Journal of Clinical Nutrition, 53, 1556S$1560 \mathrm{~S}$.
55. Mishra, S. I., Luce, P. H., \& Hubbell, F. A. (2001). Breast cancer screening among American Samoan women. Preventive Medicine, 33, 9-17.

56. Mishra, S. I., Luce-Aoelua, P., \& Hubbell, F. A. (2001). Predictors of papanicolaou smear use among American Samoan women. Journal of General Internal Medicine, 16, 320-324.

57. Mishra, S. I., Osann, K., \& Luce, P. H. (2005). Prevalence and predictors of smoking behavior among Samoans in three geographical regions. Ethnicity and Disease, 15, 305-315.

58. Balabis, J., Pobutsky, A., Kromer-Baker, K., Tottori, C., \& Salvail, F. (2007). The burden of cardiovascular disease in Hawai' $i$ 2007. Retrieved September 17, 2008, from Hawai'i State Department of Health Web site http://www.hawaii.gov/health/ family-child-health/chronic-disease/cvd/CVD2007.pdf.

59. Boyd, J. K., \& Braun, K. L. (2007). Supports for and barriers to healthy living for Native Hawaiian young adults enrolled in community colleges. Preventing Chronic Disease, 4, A102.

60. Drivsholm, T., Eplov, L. F., Davidsen, M., Jørgensen, T., Ibsen, H., Hollnagel, H., et al. (2006). Representativeness in populationbased studies: A detailed description of non-response in a Danish cohort study. Scandinavian Journal of Public Health, 34, 623631.

61. Curb, J. D., Aluli, N. M., Kautz, J. A., Petrovitch, H., Knutsen, S. F., Knutsen, R., et al. (1991). Cardiovascular risk factor levels in ethnic Hawaiians. American Journal of Public Health, 81, 164167.

62. Ogden, C. L., Carroll, M. D., Curtin, L. R., McDowell, M. A., Tabak, C. J., \& Flegal, K. M. (2006). Prevalence of overweight and obesity in the United States, 1999-2004. JAMA, 295, 15491555. 